\title{
Kesantunan dalam Berbahasa Inggris Pramusaji: Kasus pada Beberapa Café di Pantai Jimbaran, Bali
}

\author{
Ni Wayan Pastini
}

Program Studi Manajemen Tata Hidangan, Politeknik Pariwisata Bali

Jl. Dharmawangsa, Benoa, Kabupaten Badung, Bali

pastinistp26@gmail.com

\begin{tabular}{l|l} 
Received: Mei, 2021 & Accepted: Mei, 2021
\end{tabular}

Published: June, 2021

\begin{abstract}
The aim of this research is to find out the understanding and ability of the waiters or waitresses to communicate in good English, especially apologizing, offering help, offering foods and drinks and the use of greetings in good English, so as to provide better service to tourists who come to enjoy foods and beverages in cafes of Jimbaran Beach. The data of this study were the expressions used by the waiters or waitresses of some cafes in Jimbaran Beach, chosen by accidentally. The language expressions used by the waiters or waitresses were recorded, transcripted and analysed. The results showed that some waiters or waitresses used expressions incorrectly and culturally inappropriate. It indicated that their ability in communicating in English in terms of accuracy and fluency needed to be improved. In addition, they had lack of understanding of cultural differences.
\end{abstract}

Keywords: english politeness, restaurant, waiters/waitresses

\begin{abstract}
Abstrak
Tujuan dari penelitian ini adalah untuk mengetahui pemahaman dan kemampuan para pramusaji dalam berkomunikasi dengan menggunakan Bahasa Inggris terutama dalam permohonan maaf, menawarkan bantuan, menawarkan makanan, minuman serta penggunaan salam dengan benar sehingga mereka mampu memberikan pelayanan yang lebih baik kepada wisatawan yang berkunjung menikmati makanan dan minuman di cafécafé pantai Jimbaran. Data penelitian ini berupa ekspresi atau ungkapan dari para pramusaji yang dipilih secara insidental, yakni pramusaji yang dijumpai secara kebetulan di beberapa café di pantai Jimbaran. Ekspresi dari para pramusaji tersebut direkam, ditranskripsikan dan dianalisis. Hasil penelitian menunjukkan bahwa para pramusaji menggunakan ekspresi yang tidak tepat secara grammatika dan budaya. Hal ini menandakan bahwa kemampuan pramusaji dalam berkomunikasi dengan bahasa Inggris perlu ditingkatkan. Di samping itu mereka juga kurang paham dengan perbedaan budaya, khususnya dalam berkomunikasi.
\end{abstract}

Kata kunci: kesantunan berbahasa, pramusaji, restoran 


\section{PENDAHULUAN}

Keberhasilan seseorang sangat dipengaruhi oleh cara berkomunkasi dengan sesama dalam pergaulan dan dalam kehidupan manusia sehari-hari dalam masyarakat Internasional (Laoh, 2016). Berkomunikasi yang baik dan benar sangat dibutuhkan oleh masyarakat Bali terutama bagi mereka yang tinggal di daerah-daerah pariwisata. Kedatangan wisatawan mancanegara yang semakin meningkat ke Pulau ini maka bahasa Inggris yang merupakan alat komunukasi sangat dibutuhkan bagi masyarakat lokal Bali terutama di Kawasan Wisata Jimbaran, Kuta Selatan Bali, Oleh sebab itu penduduk lokal yang pada umumnya masyarakat Bali yang memakai bahasa ibu yaitu bahasa Bali maupun bahasa Indonesia sebagai bahasa nasional dipacu untuk meningkatkan kemampuan komunikasi mereka dalam berbahasa asing yaitu bahasa Inggris, kususnya masyarakat Bali yang tinggal di Jimbaran yang terlibat langsung dalam indutri Pariwisata terutama dalam pelayanan pramusaji di café-café yang berada di pantai Jimbaran. Yang diharapkan mereka dapat memberikan pelayanan yang baik untuk mewujudkan kepuasan yang diinginkan oleh para wisatawan yang menikmati sajian makan siang ataupun makan malam di café-café tersebut.

Secara teori bahwa di dunia ini masyarakat memiliki beragam budaya yang sangat berbeda dengan yang lainnya, keberagaman ini akan mempengaruhi bahasa khususnya pada aspek-aspek bahasa seperti: fonologis, morfologis, gramatika dan semantik (Hodidjah, 2019). Di antara aspek-aspek ini, aspek semantic merupakan aspek yang paling cepat dan signifikan memberi informasi tentang budaya yang mendasari suatu bahasa Batasan bahasa ditegaskan Saefullah (2010) system lambang bunyi ujaran yang digunakan untuk berkomunikasi oleh masyarakat pemakainya. Bahasa diigunakan dalam berbagai lingkungan, tingkatan dan kepentingan yang beraneka ragam, misalnya komunikasi ilmiah, bisnis, kerja, social dan budaya (Agustin, 2018)

Sebagian kecil dari perbedaan budaya dalam pemakaian bahasa dalam komunkasi sehari-hari akan dipaparkan dalam penelitian ini, yaitu tentang penggunaan modals (can. may. must, could, would) dan salam dalam menyapa seseorang dengan bahasa Inggris (LI We, 2010). Memberi salam baik selamat pagi, selamat siang, selamat sore, dan yang lainnnya dan juga menyapa atau memanggil seseorang adalah dua hal yang hampir selalu ada dalam setiap percakapan. Kedua hal ini tentunya merupakan bagian dari budaya pada semua bahasa termasuk dalam bahasa Indonesia dan bahasa Inggris, yang memiliki aturan penggunaan masing-masing (Sari, 2015). Penggunaan yang tidak tepat dapat mengakibatkan ketidaknyamanan bagi mereka yang terlibat dalam percakapan tersebut. Apalagi salam yang ada di dalam bahasa Indonesia diterjemahkan secara langsung ke dalam bahasa Inggris, misalnya selamat malam diterjemahkan menjadi good night, maka wisatawan asing itu akan merasa kaget ketika saat baru sampai di Bali sekitar pukul 7 malam disambut dengan good night, Sir, Welcome to Bali.... Hal ini terjadi karena salam good night bagi wisatawan bukanlah salam sambutan karena mereka datang pada malam hari, akan tetapi pada bahasa mereka salam ini berarti "selamat tidur" yang diucapan kalau mau berpisah dengan seseorang pada malam hari (Sugono, 2014).

Pemahaman dan penggunaan Modals (Could, Would, May. Can), salam dan sapaan dalam bahasa Inggris yang digunakan berkomunikasi sehari-hari oleh pramusaji pelayanan yang dilakukan oleh pramusaji di café-café yang berada di sekitar pantai Jimbaran yang akan menjadi pokok bahasan dalam penelitian ini. Kawasan ini memiliki wisata pantai yang sangat indah dengan sunset yang sangat indah, dan wisata budaya (upacara adat seperti ngaben, upacara dewa yadnya/upacara persembahyangan dan upacara agama lainnya). Lokasi penelitian berada di Kecamatan Kuta Selatan Kabupaten Badung. Perjalanan menuju objek wisata Jimbaran dari Bandara Internasional Ngurah Rai hanya $6 \mathrm{~km}$ yang ditempuh kira-kira sekitar 10 menit dengan kendaraan. Sebagian besar penduduk Jimbaran bekerja sebagai karyawan hotel. Karena wilayah ini banyak terdapat hotel-hotel berbintang, villa dan Homestay. 
Masyarakat Jimbaran banyak yang bekerja di sektor pariwisata seperti hotel, restoran, villa, homestay, café. Bahasa Inggris yang digunakan oleh pramusaji belum memadai oleh sebab itu sangat menarik untuk ditelitii terutama pengetahuan yang berkenaan dengan perbedaan budaya yang mendasari komunikasi yang dilakukan. Seperti yang telah dikemukakan di atas bahwa dalam tulisan ini pemahaman para karyawan di café-café di sepanjang pantai Jimbaran tersebut kurang memadai dalam pemakaian kalimat-kalimat sopan seperti memohon maaf, menawarkan bantuan, menawarkan makanan atau minuman dan pemakaian salam dan sapaan dalam bahasa Inggris. Pemahaman yang kurang memadai itu yang akan diangkat menjadi topik pembahasan penelitian ini dengan tujuan mengetahui dan meningkatkan kemampuan Bahasa Inggris pramusaji yang ada di café-café Pantai Jimbaran Bali.

\section{METODE PENELITIAN}

Penelitian ini dilakukan di beberapa café kawasan wisata Jimbaran antara lain: Menaga Café, New Bayang Café, Sari Café, Intan Café, Nyoman Café, Sakura Café, Bela Café, Teba Café, Roma Café, Surya Café, Radja Café, Rama Café, Made Café, dan Cendana Café

\subsection{Populasi}

Menurut Rusiadi dalam Aribowo (2020), populasi adalah wilayah generalisasi yang terdiri dari objek atau subjek yang mempunyai kualitas dan karakteristik tertentu yang ditetapkan oleh peneliti untuk dipelajari, dan kemudian ditarik suatu kesimpulannya. Populasi pada penelitian ini adalah para karyawan yang bekerja di beberapa café di kawasan parwisata Jimbaran, Kuta Selatan. Badung Bali.

\subsection{Sampel}

Menurut Sugiyono (2018) sampel adalah bagian dari jumlah dan karakteristik yang dimiliki oleh populasi tersebut sampel yang diambil dari populasi tersebut harus betulbetul representatif atau mewakili populasi yang diteliti. Teknik penarikan sampel yang digunakan dalam penelitian ini adalah accidental sampling (secara kebetulan), yaitu siapa saja secara kebetulan ditemui di beberapa café dan masuk dalam katagori populasi dapat dimasukkan sebagai sampel dan responden (Arikunto, 2012). Untuk itu para karyawan yang dijumpai pada saat pengumpulan data di lapangan, dapat langsung dijadikan sampel atau responden dari penelitian ini.

\subsection{Jenis Data}

Berdasarkan sifatnya jenis data dibagi menjadi dua yaitu data kualitatif dan data kuantitatif. Data kualitatif adalah data yang berbentuk label atau nama yang mendefinisikan suatu atribut atau elemen. Data bisa berupa numeric atau non numeric dengan skala pengukuran nominal atau ordinal. (dqlab.id, 2021). Jenis data yang diambil dalam penelitian kesantunan berbahasa dalam penggunaan salam dan sapaan dalam bahasa Inggris oleh para karyawan cafe di kawasan pariwisata Jimbaran adalah data kualitatif yaitu data dalam bentuk kata-kata bukan dalam bentuk angka. Data jenis ini biasanya didapatkan dengan beberapa macam teknik pengumpulan data, seperti kuesioner, wawancara, observasi, analisis dokumen, atau diskusi fokus. Data ini bisa dalam bentuk gambar dari hasil pemotretan dan rekaman. Fungsi dari data kualitatif pada dasarnya untuk mengetahui kualitas dari sebuah objek yang diteliti. Pemahaman peneliti terhadap kualitas dari objek yang diteliti benar-benar dibutuhkan, karena data jenis ini bersifat abstrak. Data yang dipergunakan dalam penelitian ini adalah data yang diperoleh dari hasil observasi dan pencatatan. 


\subsection{Sumber Data}

Menurut Narimawati dalam Pratiwi (2017) mengatakan bahwa jenis data penelitian berdasarkan sumbernya ada dua yaitu data primer dan data sekunder. Data primer merupakan data yang diperoleh peneliti dengan cara langsung dari sumbernya. Data primer biasanya disebut dengan data asli yang bersifat up to date atau masih baru untuk memperoleh data primer, peneliti wajib mengumpulkan secara langsung (Suryana, 2010), cara yang bisa digunakan peneliti untuk mencari data primer yaitu observasi, diskusi fokus, wawancara serta penyebaran kuesioner maupun merekam dengan alat perekam suara. Data yang dipergunakan dalam penelitian ini adalah data primer, yaitu data yang diperoleh langsung dari responden yang meliputi hasil dari kuesioner yang disebarkan dan wawancara dengan para karyawan di beberapa café yang berada di kawasan wisata Jimbaran, kecamatan Kuta Selatan, Kabupaten Badung, Provinsi Bali.

\subsection{Instrumen Penelitian}

Salah satu langkah penting dalam sebuah penelitian adalah menyusun instrumen penelitian (Sugiyono, 2012). Instrumen penelitian ini adalah alat bantu dalam pengumpulan data yang diperlukan dalam penelitian yang sedang dilaksanakan. Bentuk instrumen hendaknya sesuai dan terkait erat dengan metode pengumpulan data. Beberapa contoh instrumen adalah: metode angket atau kuesioner, metode wawancara, metode observasi, instrumen bernama chek-list, metode tes, instrumennya adalah soal tes, intrumen yang digunakan dalam penelitian ini adalah dengan observasi dan wawancara dengan para karyawan di beberapa cafe di kawasan pariwisata Jimbaran.

\subsection{Analisis Data}

Analisis data kualitatif menurut Saptutyningsih (2019) data kualitatif adalah data terkait dengan kejadian atau peristiwa kualitatif, seperti kejadian yang berkaitan dengan kejadian saat pramusaji melayani tamu di restoran dengan menggunakan Bahasa Inggris. Data tersebut dikelompokkan, dipilah ke dalam satuan agar bisa dikelola, mensintetiskannya, mencari dan menemukan hal - hal penting dan apa yang dapat dipelajari, serta memutuskan apa yang dapat diceritakan kepada orang lain. Dalam penelitian ini proses analisis data akan dilakukan dengan metode analisis data deskriftif. Analisis data deskritif kualitatif dianggap metode yang paling sesuai dengan karakteristik permasalahan yang diangkat dalam penelitian ini. Langkah-langkah yang akan dilakukan adalah (1) mewawancarai para karyawan di beberapa café yang berada di kawasan wisata Jimbaran, (2) data yang dikumpulkan akan dikelompokkan berdasarkan kesesuaian jawaban yang diberikan dengan situasi yang dipaparkan. (3) Berdasarkan pengelompokkan data tersebut maka akan dapat dipaparkan bagaimana kemampuan mereka dalam menggunakan bahasa yang santun dalam memberi salam dan menyapa tamu-tamu yang datang menikmati sajian di café yang ada di kawasan wisata Jimbaran.

\section{HASIL DAN PEMBAHASAN}

\subsection{Deskripsi Data}

Jimbaran merupakan salah satu desa dari kecamatan Kuta Selatan, Kabupaten Badung Propinsi Bali yang memiliki luas wilayah $20.50 \mathrm{~km} 2$ dan jumlah penduduknya 50.537 jiwa (2016) yang kepadatan penduduknya 2.165 jiwa/km (2010) dengan jumlah KK nya 11.780 KK. Desa Jimbaran memiliki 13 banjar Adat dan 14 banjar Dinas antara lain: (1) Banjar Ubung, (2). Banjar Pantai Sari, (3) Banjar Menega, (4) Banjar Pesalakan, (5). Banjar Tebe, (6) Banjar Jerokuta, (7) Banjar Tegal, (8) Banjar Perarudan, (9) Banjar Taman Griya, (10) Banjar Buana Gubug, (11) Banjar Mekar Sari, (12) Banjar Angge Sware, (13) Banjar Cengiling kusus banjar Dinas Cengiling masuk Ke jimbaran sedangkan Banjar Adatnya masuk ke Ungasan. Lokasi wilayah ini berdekatan dengan Sanur dan Nusa Dua serta Bandara Internasional Ngurah Rai. 
Desa Adat Jimbaran pada mulanya merupakan kampung nelayan kemudian berkembang menjadi daerah pariwisata, sehingga muncul banyak tempat makan hasil laut (seafood). Di Bali Selatan terdapat beberapa hotel bertaraf internasional sehingga mata pencaharian penduduk lokal sebagian besar bekerja di industri pariwisata. Di Jimbaran terdapat beberapa objek pariwisata seperti Garuda Wisnu Kencana dan Pantai Jimbaran di mana juga terdapat banyak café.

Salah satu restoran di Jimbaran Bali yang sangat direkomendasikan adalah Menega Cafe yang menyajikan menu seafood. Cafe yang berada di Jl. Four Season Resort Muaya Beach, Jimbaran, Bali yang menawarkan suasana yang tak jauh berbeda dengan tempat makan seafood di Jimbaran lainnya. Menega cafe menyajikan masakan yang diolah dengan cara dibakar/grilled. Penampilan restoran hampir sama dengan restoran lainnya dengan puluhan kursi dan meja yang tertata rapi di pinggir pantai, yang dilengkapi dengan dekorasi candle light serta lampion sebagai penerangannya. Cafe Menega sangat ramai di kunjungi.

Selain Menega Café, ada juga restoran lain yang bernama Warung Mami yang menyediakan sajian seafood seperti kakap putih, udang dan kerang putih. Untuk rasanya sudah tentu tidak diragukan lagi, menu ikan bakar atau menu grilled nya sangat enak dan lezat yang dilengkapi dengan bumbu genep khas Bali (bumbu lengkap khas Bali) yang dioleskan sebelum dibakar yang membuat citarasa seafood semakin nikmat.

\subsection{Pemaparan Data}

Data dikumpulkan dari responden dengan cara observasi, wawancara dan penyebaran kuesioner di kafe-kafe di pantai Jimbaran. Data tersebut dapat dikelompokkan menjadi dua yaitu pemahaman mereka dalam pemakaian salam dan sapaan yang formal dan informal. Kedua pemahaman tersebut diaplikasikan dalam percakapan sehari-hari dalam pelayanan pramusaji atau karyawan café terhadap para wisatawan yang menikmati makan malam di café pantai Jimbaran.

\subsection{Salam Dalam Bahasa Inggris Formal}

Data terkumpul melalui teknik pengumpulan data wawancara, pertanyaanpertanyaan yang digunakan berdasarkan acuan teori-teori linguistic yang dipaparkan dalam Bab sebelumnya. Adapaun pertanyaan-pertanyaan tersebut adalah sebagai berikut:

1) Kapan anda menggunakan salam bahasa Inggris Good Morning?

Sebagian besar dari mereka menjawab bahwa good morning sejak pagi jam 6.00 sampai jam 10.00 dan banyak juga yang menjawab bahwa good morning dipakai sejak baru bangun sampai jam 12 siang.

2) Kapan anda mengunakan sapaan bahasa Inggris Good Afternoon?

Walaupun banyak yang menjawab bahwa penggunaan good afternoon digunakan sejak jam 12.00 sampai pukul 10 atau pukul 11 malam, namun masih banyak juga yang menjawab good afternoon digunakan setelah pukul 12.00 siang sampai jam $5 /$ jam 6 Sore.

3) Kapan anda menggunakan salam bahasa Inggris Good Evening?

Banyak dari mereka menjawab bahwa pemakaian salam good evening digunakan sejak pukul 18.00 sampai larut malam. Ada juga yang menjawab bahwa good evening digunakan dari jam 18.00 sampai jam 24.00.

4) Kapankah anda menggunakan Good Bye?

Semua dari responden menjawab bahwa penggunaan salam good bye digunakan kalau mereka berpisah dengan para wisatawan pada siang hari.

5) Kapankah anda menggunakan salam bahasa Inggris Good Night?

Kebanyakan dari responden menjawab bahwa salam bahasa Inggris good night digunakan pada saat berpisah dengan para wisatawan pada saat malam dan pada saat menjelang tidur. Tapi mereka masih bingung dan memilih tidak menjawab. 


\subsection{Sapaan Bahasa Inggris Secara Formal}

1) Kepada siapa anda menyapa para tamu dengan sebutan Sir?

Semua responden memberikan jawaban bahwa sir digunakan untuk untuk menyapa seorang tamu laki-laki dan mengartikan dalam bahasa Indonesia "tuan".

2) Kepada siapa anda menyapa tamu dengan sebutan Madam?

Semua responden menjawab bahwa menggnakan sebutan madam ketika menyapa wisatawan wanita yang sudah dewasa dan berumur yang sering menterjemakan Nyonya dalam bahasa Indonesia.

3) Kepada siapa anda menyapa dengan sebutan Miss?

Semua responden menjawab bahwa mereka menggunakan sebutan Miss ketika menyapa tamu wanita yang masih muda dengan terjemahan nona.

4) Kepada siapakah anda menyapa wisatawan dengan menggunakan sebutan $M s$ ? Semua responden memberikan jawaban tidak sesuai dengan pertanyaan karena pemahaman mereka belum memadai dengan sebutan itu.

5) Kepada siapakah anda menggunakan sebutan Ladies?

Semua responden memberikan jawaban bahwa mereka menggunakan sapaan dengn sebutan ledies ketika mereka menyapa beberapa wisatawan wanita.

6) Kepada siapakah anda menyapa dengan menggunakan Gentlemen?

Para responden semua menjawab bahwa mereka menggunkan sebutan bahasa Inggris dengan Gentlemen ketika mereka bicara dengan beberapa wisatawan laki laki.

7) Kepada siapakah anda menyapa dengan menggunakan sebutan $\mathrm{Mr}$ ?

Mereka menjawab bahwa mengunakan sebutan Mr jika kita berbicara dengan wisatawan laki-laki baik mengetahui nama wisatawan tesebut maupun tidak mengetahui nama wisatawan tersebut.

8) Kepada siapakah anda menyapa wisatawan dengan sebutan Mrs?

Para pramusaji menjawab bahwa mereka menggunakan sebutan Mrs sama dengan sapaan $M r$. dan sama dengan sapaan Madam.

9) Kepada siapakah anda memanggil wisatawan dengan sebutan anak lelaki tuan John? Para responden menjawab dengan menggunakan Sir atau Mrs.

10) Bagaimana cara anda memanggil dengan sebutan bahasa Inggris dari anak perempuan Tuan John?

Semua responden menjawab bahwa penggunaan sapaan atau sebutan Madam atau Miss.

11) Bagaimana anda menyapa istri dari Tuan John?

Mereka menjawab bahwa istri Tuan John disapa dengan Mrs atau madam tanpa menyebut namanya.

\subsection{Penggunaan Salam Dan Sapaan}

Data tentang penggunaan salam dan sapaan dalam aktvitas para pramusaji atau karyawan saat melayani tamu makan siang di café-café di kawasan pantai Jimbaran. Berikut beberapa percakapan dalam melayani wisatawan makan:

1) Percakapan di Menaga Café

(Jam 17:30 ada sepasang tamu akan makan malam)

W : Good evening, Sir, Madam

$\mathrm{G}$ : Good evening we want to have some food

$\mathrm{W}$ : yes, sir.... what do you want to order?

2) Percakapan di New Bayang Café

W : Good evening Sir, Madam

$\mathrm{G}$ : Good evening

$\mathrm{W}$ : What do you want to order sir, Madam?

$\mathrm{G}:$ We want to have Indonesian food 
Ni Wayan Pastini

3) Percakapansi di Sari Café

$\mathrm{W}$ : Have you finished your dinner?

G : Yes

W : Thank you for coming and good night

4) Percakapan di Intan Café

W : Hallo Sir. Madam

G : Yes. I'll order some food and I have booked a table

$\mathrm{W}$ : Yes, sir... your table is 206.

G : Thanks

5) Percakapan di Nyoman Café

$\mathrm{W}$ : Nyoman café good evening

$\mathrm{G}:$ Do I have a table please?

$\mathrm{W}:$ Yes, $M r$.

6) Percakapan di Sakura Café

$\mathrm{G}$ : Is this Nyoman café?

W : No. It's Sakura café. Mrs,

G : Over there is Sakura café

7) Percakapan di Bela Café

W : Good Morning, Sir

$\mathrm{G}:$ I want to reserve a table fo this evening

$\mathrm{W}$ : For how many people, sir

8) Percakapan di Teba Café

W : Good evening sir, Madam. Where do you want to sit?

$\mathrm{G}:$ I wan to have a table for two

$\mathrm{W}$ : Would you like to follow me please

9) Percakapan di Roma Café

W : Good afternoon sir, madam

$\mathrm{G}$ : Where can I sit?

$\mathrm{W}$ : Where ever you like

10) Percakapan di Surya Café

W : Do you want to arder now

$\mathrm{G}$ : I am still thinking

11) Percakapan di Radja Café

$\mathrm{W}$ : Thank you you enjoyed the food

$\mathrm{G}$ : You are welcome

12) Percakapan di Rama Café

W : What would you like to oder?

G : I am thinking

13) Percakapan di Made Café

W : Good Afternoon

$\mathrm{G}$ : Can I see the menu list

$\mathrm{W}$ : Yes, here you are

14) Percakapan di Cendana Café

$\mathrm{W}$ : Thank you for coming

$\mathrm{G}:$ You are welcome

$\mathrm{W}$ : Good bye

\subsection{Analisis Data}

Pembahasan pada analisis ini berdasarkan data yang diperoleh dalam penelitian ini mengacu ke teori yang dipaparkan sebelumnya yaitu tentang pemahaman para karyawan cafe yang berada di Jimbaran dalam pemberian salam dan sapaan secara formal dalam bahasa Inggris. Data ini terkumpul berdasarkan teknik pengumpulan data wawancara, 
pertanyaan-pertanyaan yang digunakan berdasarkan landasan teori sebelumnya. Adapun pertanyaan-pertanyaan yang digunakan tersebut adalah sebagai berikut:

1) Penggunaan salam bahasa Inggris "Good Morning"

Sebagian besar dari responden menjawab bahwa "good morning" sejak pagi jam 6.00 sampai jam 10.00 dan banyak juga yang menjawab bahwa "good morning" dipakai sejak baru bangun sampai jam 12 siang. Berdasarkan jawaban yang diberikan oleh responden dapat dikatakan bahwa mereka masih kurang dalam pemahaman penggunaan salam "good Morning" karena menurut teori bahwa "good morning" digunakan sejak pukul 06.00 sampai pukul 12.00. dan beberapa dari mereka sudah memahami penggunaan kata salam good morning karena ada dari mereka menggunakan salam "good morning" dari pukul 06.00 sampai pukul 12.00 .

2) Penggunaan salam bahasa Inggris "Good Afternoon"

Walaupun banyak yang menjawab bahwa penggunaan "good afternoon" digunakan sejak pukul 12.00 sampai pukul 20.00 atau pukul 21.00 malam, namun masih banyak juga yang menjawab "good afternoon" digunakan setelah pukul 12.00 siang sampai pukul 17.00/18.00. Berdasarkan penjelasan ini bahwa karyawan café tidak semuanya memahami salam yang formal dalam bahasa inggris karena ada beberapa responden yang menjawab benar sesuai teori dan ada juga yang salah karena "good afternoon" seharusnya digunakan dari pukul 12.00 siang sampai pukul 18.00 atau saat matahari terbenam.

3) Penggunaan salam bahasa Inggris "Good Evening"

Banyak dari mereka menjawab bahwa pemakaian salam "good evening" digunakan sejak pukul 18.00 sampai larut malam. Ada juga yang menjawab bahwa "good evening" diucapkan dari pukul 18.00 sampai pukul 24.00. Berdasarkan jawaban dari responden bahwa bahasa Inggris "good evening" dapat diucapkan dengan benar dapat diartikan mereka sudah memahami salam tersebut yang sesuai dengan teori Bahasa. "Good evening" dapat digunakan dari pukul 18.00 sampai pukul 24.00 karena saat itu mereka belum berpisah. Kalau mereka berpisah sebelum pukul 24.00 mereka boleh menggunakan "good night".

4) Penggunaan salam bahasa Inggris "Good Bye"

Semua dari karyawan café menjawab bahwa penggunaan salam good bye digunakan kalau mereka berpisah dengan wisatawan. Berdasarkan dari jawaban tersebut dapat dikatakan karyawan café dapat memahami salam good bye. Tetapi menurut teori good bye dapat digunakan saat berpisah sebelum pukul 20.00.

5) Penggunaan salam bahasa Inggirs "Good Night"

Kebanyakan dari responden menjawab bahwa salam bahasa Inggris "good night" digunakan pada saat berpisah dengan wisatawan pada saat malam dan pada saat menjelang tidur. Tapi mereka masih bingung dan memilih tidak menjawab. Berdasarkan dari jawaban responden bahwa mereka sudah memahami penggunaan salam dalam bahasa Inggris "good night" namun mereka belum menguasai pemahaman seutuhnya karena "good night" dapat digunakan saat berpisah setelah pukul 20.00, tetapi kalau berpisah sebelum pukul 20.00 kita dapat menggunkan "good bye".

6) Penggunaan sebutan "Sir"

Semua responden memberikan jawaban bahwa "Sir" digunakan untuk untuk menyapa seorang tamu laki-laki dan mengartikan dalam bahasa Indonesia "tuan". Berdasarkan jawaban responden dapat dikatakan sudah memahami hanya sebagian tentang "Sir", karena menurut teori "Sir" bisa digunakan untuk menyapa tamu jika belum mengetahui nama tamu tersebut, jikalau kita sudah mengetahui nama tamunya kita dapat menyapa dengan menggunakan " $M r$ " yang diikuti oleh nama tamu tersebut. Contoh: Mr. Lennon (yang namanya John Lennon), Mr. John Brown (jika nama tamunya John Browm). 
7) Penggunaan sebutan "Madam"

Semua responden menjawab bahwa menggnakan sebutan Madam ketika menyapa wisatawan wanita yang sudah dewasa dan berumur yang sering menterjemakan Nyonya dalam bahasa Indonesia. Berdasarkan dari jawaban responden bahwa mereka belum memahami seutuhnya teori pemakaian sapaan dalam bahasa Inggris karena menurut teori Madam digunakan untuk menyapa seorang tamu wanita dewasa namun namanya belum diketahui. Jikalau seorang tamu wanita dewasa yang sudah diketahui namanya maka bisa disapa dengan Mrs. Lennon.... (istri dr John Lenonn). Mrs. Smith (istri dari Mr. John Smith).

8) Penggunaan sebutan "Miss"

Semua responden menjawab bahwa mereka menggunakan sebutan "Miss" ketika menyapa tamu wanita yang masih muda dengan terjemahan nona. Berdasarkan jawaban dari responden bahwa karyawan café sudah memahami dengan benar sesuai dengan teori tersebut.

9) Penggunaan sebutan " $M s$ "

Semua responden menjawab tidak sesuai dengan pertanyaan karena pemahaman mereka belum memahami sebutan itu. Berdasarkan jawaban dari responden yang membingungkan maka bisa dikatakan semua responden belum memahami penggunaan salam " $M s$ " ini. Menurut teori "Ms" digunakan untuk tamu wanita dewasa baik yang sudah bersuami ataupun belum.

10) Penggunaan sebutan "Ladies"

Semua responden memberikan jawaban bahwa mereka menggunakan sapaan dengan sebutan "ladies" ketika mereka menyapa beberapa wisatawan wanita. Berdasarkan jawaban dari responden bahwa mereka sudah memahami penggunaan sapaan formal dalam bahasa Inggris untuk beberapa wanita yaitu "ladies"

11) Penggunaan sebutan "Gentlemen"

Para responden semua menjawab bahwa mereka menggunkan sebutan bahasa Inggris dengan "gentlemen" ketika mereka bicara dengan beberapa wisatawan laki-laki. Berdasarkan jawaban semua responden terhadap penggunaan sapaan "gentlement" dapat dikatakan mereka sudah sangat memahami tentang sapaan untuk beberapa tamu laki-laki yang sudah dewasa.

12) Penggunaan sebutan " $M r$ "

Mereka menjawab bahwa mengunakan sebutan " $M r$ " jika kita berbicara dengan wisatawan laki-laki baik mengetahui nama wisata tesebut maupun tidak mengetahui nama wisatawan tersebut. Berdasarkan dari jawaban semua responden terhadap penggunaan " $M r$ " untuk menyapa tamu laki-laki yang sudah dewasa dapat dikatakan bahwa mereka sudah memahami teori sapaan namun tidak sepenuhnya benar karena " $M r$ " dapat dipakai untuk menyapa tamu laiki - laki yang sudah diketahui namanya. Jika namanya tidak diketahui maka dipakai sapaan "Sir".

13) Penggunaan sebutan "Mrs"

Para responden menjawab bahwa mereka menggunakan sebutan "Mrs" dengan sapaan "Mr" dan sama dengan sapaan "Madam". Berdasarkan jawaban dari responden terhadap pemakaian sapaan formal "Mrs" dapat dikatakan para karyawan belum memahami teori tentang sapaan secara formal. Menurut teori Mrs digunakan untuk menyapa tamu wanita dewasa yang sudah diketahui namanya. Contoh: Mrs. Lennon (istri tuan John Lennon)

14) Penggunaan sebutan Anak Lekai Tuan John

Para responden menjawab dengan menggunakan "Sir" atau "Mrs". Berdasarkan jawaban responden dapat dikatakan sudah benar sesuai teori hanya penggunaan " $M r$ " harus diikuti dengan nama keluarganya.

15) Penggunaan sebutan Anak Perempuan Tuan John 
Semua responden menjawab bahwa penggunaan sapaan atau sebutan "Madam" atau "Miss". Berdasarkan jawaban dari para karyawan café dapat dikatakan mereka sudah memahami teori tentang sapaan secara formal dalam bahasa Inggris.

16) Penggunaan sebutan Istri Tuan John

Mereka menjawab bahwa istrinya Tuan John disapa dengan "Mrs" atau "madam" tanpa menyebut namanya. Berdasarkan jawaban dari responden dapat dikatakan bahwa para karyawan café sudah memahami teori sapaan formal bahasa Inggris.

\section{KESIMPULAN}

Secara umum para pramusaji sudah memahami dalam penggunaan salam secara formal, tetapi ada beberapa dari mereka masih bingung dalam pemakaian sapaan "Good Morning" karena mereka memahami dan mengartikannya sebagai selamat pagi dalam Bahasa Indonesia yang diucapkan dari pukul 07.00 sampai pukul 10.00 sedangkan pukul 11.00 sudah menggunakan sapaan "Good Afternoon" yang diartikan sebagai selamat siang. Menurut teori seharusnya "Good Morning" digunakan dari pukul 06.00 sampai pukul 12.00 siang. Berdasarkan analisa pada bab sebelumnya bahwa para pramusaji tidak sepenuhnya memahami penggunaan sapaan. Karena beberapa dari mereka masih menggunakan " $M r$ " dan "Mrs" saat menyapa tamu/wisatawan di mana yang seharusnya mereka menyapa menggunakan sapaan "Sir" atau "Madam". Dari semua percakapan yang diambil dari aktivitas para pramusaji pada saat melayani tamu/wisatawan yang datang mereka tidak menggunakan kaidah-kaidah salam dan sapaan yang sesuai menurut teori Bahasa Inggris., karena mereka belum memahami sepenuhnya teori dalam bahasa Inggris tersebut. Disarankan kepada pemilik café dan dinas Pariwisata untuk menyelenggarakan kursus singkat Bahasa Inggris karena bahasa merupakan alat komunikasi antara tamu dan pramusaji yang seharusnya digunakan sapaan dan salam dengan baik dan benar akan memberikan kesan yang baik terhadap industri pariwisata.

\section{DAFTAR PUSTAKA}

Agustin, D. 2018. Manfaat Bahasa Inggris Dalam Bidang Pelayanan Di Food And Beverage Department Hotel Bandung Permai Jember.

Arikunto, Suharsimi. 2012. Prosedur Penelitian. Jakarta: Rineka Cipta

Dqlab. 2021. Mengenal Jenis-Jenis Data Dalam Pengolahan Data Statistik. Diakses 1 Oktober 2021 dari: https://www.dqlab.id/mengenal-jenis-data-dalam-pengolahanstatistik

Hodidjah. 2019. Bahasa Mempengaruhi Budaya Atau Sebaliknya. https://sumsel.kemenag.go.id/files/sumsel/file/file/TULISAN/tdga1335500676.pd $\mathrm{f}$

Laoh, M. 2016. Pentingnya Penguasaan Bahasa Inggris Bagi Pramusaji di Restoran Pada Hotel Berbintang di Bali. Jurnal Polimdo

LI We. 2010. The Function of Greeting. Canada Social Science. Vo; 6 no 4.2010 (pp.56-62)

Pratiwi, Indah, Nuning. 2017. Penggunaan Media Video Call dalam Teknologi Komunikasi. Jurnal Ilmiah Dinamika Sosial Vo. 1 No. 2.

Saefullah, Nurul Hikmayaty. 2010. Keragaman Sapaan dalam Tuturan Seputar Kegiatan Perdagangan di Pasar Banjaran, Kabupaten Bandung. Laporan Penelitian. Bandung, Universitas Padjajaran

Saptutyningsih, Endah. Setyaningrum, Esty. 2019. Penelitian kuantitatif metode dan alat analisis: dilengkapi dengan contoh proposal penelitian / oleh Endah Saptutyningsih, Esty Setyaningrum. Sleman: Gosyen Publishing

Sari, Puspita, Inda. 2015. Pentingnya Pemahaman Kedudukan Dan Fungsi Bahasa Indonesia Sebagai Pemersatu Negara Kesatuan Republik Indonesia (NKRI). Prosiding Seminar Nasional Bulan Bahasa UNIB 
Ni Wayan Pastini

SM, Aribowo. 2020. Pengaruh Loyalitas Dan Integritas Terhadap Kebijakan Pimpinan Di Pt. Quantum Training Centre Medan. Jurnal Ilmiah Manajemen dan Bisnis Vol 1 No 1. Sugiyono. 2012. Metode Penelitian Kualitatif dan Kuantitatif. Bandung: Alfabeta

Sugiyono. 2018. Metode Penelitian Kuantitatif, Kualitatif, dan R\&D. Bandung: Alfabeta.

Sugono, Dendy. 2014. Kamus Besar Bahasa Indonesia Pusat Bahasa. Edisi Keempat. Cetakan kedelapan. Jakarta: Gramedia Pustaka Utama.

Suryana. 2010. Data dan Jenis Data Penelitian. Diakses 1 Oktober 2021 dari: https://csuryana.wordpress.com/2010/03/25/data-dan-jenis-data-penelitian/ 